\title{
Relationship between Labor and Economic Growth in Vietnam: Practice and Forecast
}

\author{
Phuong Huu Tung
}

\section{ABSTRACT}

\begin{abstract}
This paper analyzes the effects of the fluctuation in labor force and labor productivity on Vietnam's economic growth. Using the neoclassical growth model with data from the General Statistics Office, the study shows that when the number of laborers increases by $1 \%$, the economic growth rate will raise by $\mathbf{2 . 7 8 \%}$. Combined with predicted figures on changes in Vietnam's labor force in the period of 2009-2049, the results of the study reveal in order to maintain the current economic growth rate, labor productivity needs to increase to $106.2 \%$ in the period of $2029-2039$ and $111.6 \%$ in the period of 2039-2049. Vietnam is losing the advantage of labor force so its long-term economic growth will depend mainly on labor productivity. Improving the quality of labor is the driving force for economic growth. This depends on the combination of specific national policies and strategies, in which education and training policies are highlighted.
\end{abstract}

Keywords: Economic growth; Labor; Labor productivity; Vietnam.
Submitted : July 26, 2021

Published : August 17, 2021

ISSN: 2507-1076

DOI: $10.24018 /$ ejbmr.2021.6.4.995

\section{Phuong Huu Tung*}

Hanoi University of Home Affairs, Hanoi, Vietnam.

(e-mail: phuonghuutung ${ }^{\circledR}$ gmail.com)

*Corresponding Author

\section{INTRODUCTION}

After many development stages of economic history, from the Classical Growth Theory $\left(18^{\text {th }}\right.$ century) to the Endogenous Growth Model (late $20^{\text {th }}$ century), the growth theories and models affirm the importance of labor - one of the basic inputs that determine economic growth in a country. The birth of the Neoclassical growth model (mid-20 $0^{\text {th }}$ century) is considered the first complete economic growth model, focusing on four variables namely Output (Y), Capital $(\mathrm{K})$, Labor (L), and Technology (A) with a starting point from the Cobb-Douglas production function $\left(Y=A \cdot K^{\alpha} L^{\beta}\right)$. From this basic equation, several economic studies have based on developing the model to calculate the contribution of the factors to the growth.

In Vietnam, after the reunification day, especially since the implementation of economic reform, the labor force has grown continuously in terms of scale and proportion over the total population. The sharp increase in the labor force together with the policies of innovation, openness, and development contributed significantly to the national economic growth over the past 30 years.

Figures showed an impressive economic growth rate of Vietnam with an average of about $7 \%$ per year, including a great contribution of the labor force. Therefore, during this period, many studies proudly mentioned the huge advantage of Vietnam with "abundant labor force, cheap labor..." because it was one of the significant reasons to attract foreign investment, promote the development of processing and labor-intensive manufacturing industries. However, in recent years, fewer and fewer scientists use the term "advantage" when mentioning cheap labor in the nation. Instead, they express anxiety and concern because it is impossible for Vietnam's labor force to be permanently abundant, and, in addition, cheap is not considered an advantage but a big challenge on the way of integration and development. Vietnam is facing up with "middle income trap" and the risk of "getting old before getting rich" due to low labor skills and low labor productivity.

If the study simply bases on the perspective of labor force size, it can be seen that there has been a drastic transformation in the process of population change in Vietnam over the past three decades, resulting in a rise in the labor force over the total population. Many studies point out that Vietnam has a period of "golden population structure" which lasts for more than 30 years (about 2009-2039), that is, during such period, the labor force accounts for a large proportion of the total population with "more than two working-age people bearing one dependent only". This is a great advantage for Vietnam if it can exploit this resource for economic growth and development. However, if the labor quality is not improved and labor capacity is not promoted better to create high productivity, the term "golden population structure" will be no longer accurate, but only "copper" or "iron", as once feared by some leading scientists. On the other hand, what will Vietnam's economic growth be like when the "golden population structure" period is over? In the long term, when there is no advantage in labor resources, how should the labor quality be improved so that the country can maintain the current economic growth rate? This paper studies the fluctuation of Vietnam's labor resources in relation to economic growth, and analyzes labor quantity, labor productivity, and calculates the contribution of labor to economic growth in the past, at present, and in the future (predicted data) to clarify these issues. 


\section{RESEARCH Method AND ESTIMATION MODEL}

In the calculation models and expressions, this study assumes that all working-age people are engaged in economic activities, so the Labor variable (L) is interpreted as a variable representing the population group in the working age (from 15 to 60 years old).

To estimate the impact of labor on economic growth through the number of laborers and labor productivity in Vietnam, the study bases on the theoretical framework of the neoclassical growth model with the starting point of the Cobb-Douglas production function:

$$
Y=A K^{\alpha} L^{\beta}
$$

where $\mathrm{Y}$ is output (real GDP), capital (K), and labor (L) are inputs. $\mathrm{A}$ is a parameter reflecting technology and are parameters reflecting the elasticity of output according to capital and labor, respectively.

With $\mathrm{P}$ being the total population, equation (1) can be rewritten as follows:

$$
Y=A K^{\alpha} P^{\beta}(L / P)^{\beta}
$$

To clarify the relationship between the growth rate of the factors and the growth rate of GDP per capita, logarithms is made on two sides of equation (2) as follows:

$$
L n Y=\ln A+\alpha \ln K+\beta \ln P+\beta \ln (L / P)
$$

The study uses the above-mentioned form of the function to estimate the impact of factors on economic growth, in which the proportion of the working-age population (number of people aged 15 to 60 over the total population- aw) is used as a variable representing the labor force to population ratio (L/P).

Then, the specific form of the empirical production function to estimate will be:

$$
\operatorname{Ln}(Y)=a+b_{1} \ln K+b_{2} \ln P+b_{3} \ln (a w)+e
$$

In which:

a: that reflects the change of the dependent variable not explained by the independent variables in the model and the coefficients $b_{1}, b_{2}, b_{3}$ : respectively are elasticity coefficients of real GDP according to the independent variables in the model.

Besides, with being real GDP per capita, simple mathematical transformation can be made to show labor productivity and labor force to population ratio for growth through the following equation:

$$
y=\frac{Y}{P}=\frac{Y}{L} \times \frac{L}{P}
$$

Equation (5) shows the dependence of the economic growth rate on two components: labor productivity and labor force to population ratio. Thus, if labor productivity (Y/L) is constant, economic growth depends on the growth rate of the labor force to population ratio. This confirms that: in any country, the bigger number of laborers in the total population is, the more per capita income gets. So, $L / P$ is called the Economic support ratio that shows how many people of working age 'burden' the entire population economically.

From equation (5) logarithm is made on two sides, the equation showing the growth rate of the GDP per capita as follows:

$$
g_{Y}=g_{Y / L}+g_{L}-g_{P}
$$

Equation (6) shows that the economic growth rate is determined by the growth rate of labor productivity and the difference between the labor growth rate and the population growth rate. If the labor growth rate is equal to the population growth rate, then economic growth depends on labor productivity only. On the other hand, if the labor growth rate is slower than the population growth rate in general, then economic growth is constrained by the increase in the number of dependents (children and the elderly) in the total population.

The later part of the paper will present the results of estimating the impact of labor on Vietnam's economic growth through the correlation between labor growth rate and growth rate of GDP per capita. Nevertheless, equation (6) is used in combination with the data source of the Vietnam Population Census for the period 1979-2009 and the predicted data for the period 2009-2049 of the General Statistics Office to calculate the contribution of the labor productivity, labor ratio, and population in general to the growth of the economy.

\section{LABOR FORCE AND LABOR PRODUCTIVITY IN VIETNAM: OPPORTUNITIES AND CHALLENGES FOR ECONOMIC GROWTH}

\section{A. The Labor Force}

The labor force of Vietnam has continuously increased since before 1979. This fact was an inevitable result of the "population explosion" phenomenon that began in the 1960s, derived from too high fertility and low death rates. According to the statistics, the average number of children per woman in period 1960-1969 was 6.6 and in 1969-1979 was 5.8 [1]. The number of newborns every year boosted so fast that as a result, after 15 years, the number of people entering the working age would increase accordingly.

Hence, the average numbers of employees increased were $820,000 /$ year in the period $1979-1989,980,000 /$ year in the period 1989-1999 and in the period 1999-2009 about 1.3 million laborers were added to the labor force in Vietnam every year in average. For the period 1979 - 2009 in general, the population raised by 1.6 times while the number of people of working age increased by 2.1 times, but in the period of 1999-2009 especially the growth rate of the working-age population doubled which of the general population.

As a result of the strict execution of fertility reduction in our country, there was an evident decline in the number of newborns every year. In the period of 1979-1989, the average number of children per woman decreased to 4.3. This figure decreased to 3.1 in the period of 1989-1999 and 2.18 only ten years later. This is the basic reason for the growth rate of the population and the working-age population to decline over the years although both have increased sharply in terms of size. 
TABLE I: LABOR AND POPULATION CHANGES IN VIETNAM, 1979-2049

\begin{tabular}{|c|c|c|c|c|c|c|c|c|c|}
\hline No & Year & 1979 & 1989 & 1999 & 2009 & 2019 & 2029 & 2039 & 2049 \\
\hline 1 & $\begin{array}{c}\text { Population (P) (Mil } \\
\text { people) }\end{array}$ & 53,74 & 64,38 & 76,33 & 85,85 & 95,47 & 102,65 & 107,02 & 107,88 \\
\hline 2 & Labor (L) (Mil people) & 27,13 & 34,51 & 44,56 & 56,70 & 62,84 & 65,45 & 65,76 & 61,89 \\
\hline 3 & $\begin{array}{l}\text { Proportion of labor in } \\
\text { total population }\end{array}$ & 50,49 & 53,60 & 58,38 & 66,05 & 65,83 & 63,76 & 61,45 & 57,37 \\
\hline 4 & Labor growth rate $(\%)$ & - & 2,40 & 2,56 & 2,41 & 1,03 & 0,41 & 0,05 & $(0,61)$ \\
\hline
\end{tabular}

Source: Calculated from the 1979-2019 Population Census data and population forecast data of the General Statistics Office, 2020c.

The data in Table I shows that, although the labor growth rate has decreased strongly over the years, the number of labourers will continue to increase until 2039 with a peak of 65.76 million, then the labor force size will decrease gradually and rapidly as the labor force reaches retirement age while its annual additional source declines greatly as a result of fertility reduction policy. With this fact, Vietnam will experience the

\section{B. Labor Productivity and Labor Quality}

Though a young and abundant labor force is identified as a national advantage, in order to exploit this advantage, it is necessary to integrate two conditions in terms of labor force scale and labor quality. If the workers are well-trained and have good professional qualifications, Vietnam may become a production partner with developed countries in some key industries. The large and skilled labor force will help Vietnam penetrate faster and deeper into the regional and global economy. Furthermore, the rise in the quantity of employed labor force with higher and higher incomes will make a major contribution to the social security fund, contribute to the strong assurance of the pension financial system in the long term.

Our labor force, however, has low technical qualifications and a lack of skills. The proportions of labor with professional and technical qualifications in Vietnam were $22.8 \%$ in 2018, $15.5 \%$ in 2009 , and $10 \%$ in 1999 , showing a slow-moving improvement in the labor quality in comparison with the speed of economic growth and labor restructuring.

In 2018 , there were more than $77 \%$ of untrained employed workers in the nation, in which the proportion of trained workers in urban and rural areas was significantly different. The country faces a great challenge in meeting the goal of sustainable development. In addition, trained workers are still poor in quality with proximately $40 \%$ of them with weak qualifications. Thousands of graduates from economics, business administration, etc. every year are unable to find jobs due to unrealistic training, while businesses cannot recruit enough skilled workers. This situation is a consequence of inadequacies in the education system. The majority of Vietnamese technical employees working in hightech enterprises usually only perform simple tasks such as operating simple machines, equipment, and repairs, while complicated stages required high technical skills are mostly undertaken by foreign workers, which shows that Vietnamese workers are losing their advantages right at "home base" and, along with that, their income sources are also limited.

With low technical and professional qualifications, the limited amount of human capital accumulated in the labor force makes Vietnam's labor productivity not high. Vietnam's labor productivity in 2018 was estimated at VND 102.2 million/person, an increase of 5.93\% compared to 2017 [7]. Labor productivity growth has recovered and increased rapidly in recent years, reaching an average of $4.77 \% /$ year from 2011 to 2018 (compared to $3.17 \%$ / year in the 2007 2010 period).

However, the Ministry of Labor, Invalids, and Social Affairs assessed that Vietnam's labor productivity is still far behind many ASEAN countries. At 2010 comparative prices, in 2018 Vietnam's labor productivity was 1/30 times that of Singapore, $29 \%$ of Thailand's labor productivity, $13 \%$ of Malaysia's labor productivity, $44 \%$ of the Philippines' labor productivity. During the past 15 years, our country's productivity growth rate has always been lower than the economic growth rate. This shows the fact that Vietnam's economy is growing based on expanding production scale, using more labor rather than developing in depth, basing on labor productivity. Therefore, it is necessary to improve the quality of labor by increasing the number of trained workers, improving the quality of training, etc., which is an urgent work to improve labor productivity, thereby integrating with the increased workforce during the "golden population structure" period to accelerate economic growth.

\section{IMPACT OF LABOR ON THE ECONOMIC GROWTH OF VIETNAM: HISTORY, SITUATION, AND PREDICTION}

The study uses the ordinary least squares (OLS) method to estimate the production function (4) with the data source collected mainly from GSO Statistical Yearbook, including collected population data by age group of 63 provinces/ cities in the 2007-2009 period and data on GDP, the ratio of investment to GDP by the province in the 2007-2009 period. The estimation results are shown in the following table:

TABLE II: RESULTS OF ESTIMATING THE IMPACT OF FACTORS ON VIETNAM'S ECONOMIC GROWTH

\begin{tabular}{ccccccc}
\hline \hline ln_gdp & \multirow{2}{*}{ Coef. } & $\begin{array}{c}\text { Std. } \\
\text { Err. }\end{array}$ & $\mathrm{t}$ & $\mathrm{P}>\mathrm{t}$ & $\begin{array}{c}{[95 \%} \\
\text { Conf. }\end{array}$ & Interval] \\
\hline $\ln \_\mathrm{k}$ & 0,406 & 0,046 & 8,840 & 0,000 & 0,315 & 0,496 \\
$\ln \_\mathrm{p}$ & $-1,999$ & 0,545 & $-3,670$ & 0,000 & $-3,074$ & $-0,924$ \\
$\ln \_\mathrm{aw}$ & 2,782 & 0,532 & 5,230 & 0,000 & 1,733 & 3,832 \\
_cons & 4,542 & 0,814 & 5,580 & 0,000 & 2,936 & 6,148 \\
\hline \hline
\end{tabular}

(Source: Authors' estimation results, 2020).

It is shown in the estimation results that the estimated coefficients in the model, which are actually non zero, are at the rate of $5 \%$ statistically. $\mathrm{R} 2=0.8273$ indicates that the independent variables in the model explain $82.73 \%$ of the variation of the dependent variables.

The estimation results can be written in the form of the equation as follows:

$$
\operatorname{Ln}(G D P)=4,542+0,406 \ln K-1,999 \ln P+2,782 \ln (a w)
$$


The positive coefficient of the working-age population ratio variable (aw) is at the rate of 5\% statistically, showing the positive role of labor supply in economic growth. In the context of other factors remaining unchanged, when the proportion of people of working age increases by $1 \%$, the economic growth rate will increase by $2.78 \%$.

The negative coefficient of LnP variable implies that the too fast population growth will negatively affect the economic growth. Provided that other factors remain constant, when the total population growth rate increases by $1 \%$, the economic growth rate will decrease by $1.99 \%$. The table of estimation results also shows that investment brings a positive impact on economic growth. Specifically, in the context of other factors unchanged, the $1 \%$ increase in the rate of investment capital will increase GDP growth rate by $0.4 \%$. From this result, it can be asserted that, when the labor force increases, the saving will increase, which is an important indirect channel that has a positive impact on economic growth.

On the other hand, in order to prove labor's contribution to the economic growth expressed through two indicators: labor quantity and quality (productivity), the study uses equation (6) in combination with Data in Table I for specific calculations for the period of 1989-2009 and forecasts for the period of 2009-2049 (assuming GDP stays at the average level of the period 1999-2009). Calculation results are shown in Table III below.

Vietnam's labor growth rate has passed its peak period (2.56\%/ year in the 1989-1999 period) and in the coming decades, the labor growth rate will continue to decrease. After
2039, Vietnam will have absolutely no advantage in terms of labor size with the contribution of labor size to economic growth after 2039 being negative. This confirms the role of labor quality in Vietnam's economic growth in the long term.

Abundant labor force contributed about $43 \%$ to Vietnam's economic growth in 1989-1999. However, if the whole population is considered a unity in which workers engage in economic activities and "burden" their dependents (the elderly and children), after deducting the portions for dependents, the remaining contribution to economic growth during this period is about $15 \%$ only. Similarly, the labor force contributed to Vietnam's economic growth in the periods of 1999-2009 and 2009-2019 were 40\% and 17\% respectively. However, after subtracting the "dependent burden", the contribution to economic growth in the period of 1999-2009 was $21 \%$ and at the end of the period of 20092019 , as the labor force decreased sharply, together with the increase in dependent burden from the elderly, this contribution was zero. After 2019, Vietnam's economic growth will depend mainly on labor productivity.

Labor productivity contributed $85 \%$ to economic growth in 1989-1999 and this figure was $100 \%$ in 2019. After 2019, along with a decrease in the number of laborers, there will be a sharp increase in the number of dependents at old age in Vietnam due to population aging. At that time, to maintain the current economic growth rate, Vietnam's labor quality needs to be strongly improved; labor productivity needs to increase to $105 \%$ from 2019 to 2029 and to $110 \%$ in the period 2039-2049. This fact raises the problem of improving the quality of human resources in Vietnam.

TABLE III: CONTRIBUTION OF FACTORS TO VIETNAM'S ECONOMIC GROWTH, 1989-2049

\begin{tabular}{ccccccccc}
\hline \hline Period & & $1979-1989$ & $1989-1999$ & $1999-2009$ & $2009-2019$ & $2019-2029$ & $2029-2039$ & $2039-2049$ \\
\hline \multirow{2}{*}{ Average } & $\mathrm{g}_{L}$ & 2,40 & 2,56 & 2,41 & 1,03 & 0,41 & 0,05 & $-0,61$ \\
growth rate & $\mathrm{g}_{P}$ & 1,81 & 1,7 & 1,18 & 1,06 & 0,73 & 0,42 & 0,08 \\
$(\% /$ year $)$ & $\mathrm{g}_{Y / L}$ & - & 5,09 & 4,75 & 6,07 & 6,33 & 6,38 & 6,70 \\
& $\mathrm{~g}_{Y / P}$ & - & 5,95 & 5,98 & $6,10^{*}$ & $6,10^{*}$ & $6,10^{*}$ & $6,10^{*}$ \\
Contribution & $L$ & - & 43,03 & 40,30 & 16,89 & 6,72 & 0,82 & $-10,0$ \\
to economic & $P$ & - & $-28,57$ & $-19,73$ & $-16,39$ & $-11,97$ & $-6,89$ & $-1,31$ \\
growth $(\%)$ & $Y / L$ & - & 85,55 & 79,43 & 100,50 & 103,77 & 104,59 & 109,84 \\
& $Y / P$ & - & 100 & 100 & 100 & 100 & 100 & 100 \\
\hline \hline
\end{tabular}

Source: Calculation from data in Table 1 and Vietnam's economic growth data in the period of 1990-2009 of General Statistics Office, 2010. $\left(^{*}\right)$ the data assumes GDP remained at the level of the period 2008-2018 is $6.01 \%$ (GSO).

\section{CONCLUSION AND RECOMMENDATIONS}

In the cause of industrialization, modernization, and international economic integration, an abundant human resource is the national advantage of Vietnam. The number of laborers increased dramatically in the period of stable political status, economic reform, and expansion of exchanges with the world economy, creating a new position and force for Vietnam to accelerate economic growth from 1989 to 2009. The contribution of labor size to economic growth in this period was over $40 \%$. In the next 30 years, the number of laborers in our nation will continue to rise, reaching a peak in 2039 with 65.76 million, a good opportunity for economic growth and national development. However, the number of laborers is only a necessary condition while improving the quality of human resources is the sufficient condition to best exploit the opportunities from growth labor.
Vietnamese labor quality is currently the most important issue that requires regulation through specific policies and strategies. The quality of the available labor force does not meet production requirements, in which, labor productivity is low, workers are both physically and professionally weak, and lack necessary skills. Without improving labor quality, Vietnam will not be able to sustain economic growth and will deal with lots of challenges such as unemployment; social evils, the burden of "dependent population" ... and when this force joins the elderly, the burden of retirement finance, medical expenses and social security issues will become serious.

In the manufacturing sector alone, in order to maintain the growth rate as in the past time, labor productivity must increase by $105-110 \%$ (2019-2049) if other factors remain unchanged.

Human resource development is the driving force for economic growth, the most urgent issue of our country's goal of economic growth and development. Therefore, it is 
necessary to take the initiative and innovation in policies and actions, ensure abundant human resources, high quality, and high employment growth rate to be able to continue to exploit the advantages of labor and increase the competitiveness of the economy and promote integration and development.

Education and training policies should give priority to vocational training and job creation for workers; strengthen professional training and skills for learners in order to increase labor productivity and link training with practical social needs. Attention should be also paid to labor employment policies, production promotion, and cooperation in developing science and technology, promotion of international cooperation on labor, etc., to gradually improve labor quality and ensure the quality of Vietnam's economic growth in the long term.

\section{REFERENCES}

[1] Nguyen, Dinh $\mathrm{Cu}, 50$ years of fertility reduction policy in Vietnam (1961-2011): Achievements, impacts and lessons learned, National Economics University Publishing House, Hanoi, 2011, pp. 15-18.

[2] Tran Tho Dat, Economic growth models, National Economics University Publishing House, Hanoi, 2008, pp. 6-9.

[3] Bui Thi Minh Tiep, Impact of changes in population size and structure on Vietnam's economic growth, National Economics University Publishing House, Hanoi, 2012, pp. 72-75.
[4] Vietnam general Statistics Office, Vietnam's Population Forecast for the period of 2009-2049, Ministry of Planning and Investment, Vietnam, Hanoi, June, 2010.

[5] Vietnam general Statistics Office, Vietnam's Population Forecast for the period of 2014-2049, Ministry of Planning and Investment, May 2016.

[6] Vietnam general Statistics Office, Labor force and employment survey report 2016, Ministry of Planning and Investment, May 2017.

[7] Vietnam Institute of Labor Science and Social Affairs, Vietnam's Labor and Social Trends Report 2012-2017. Ministry of Labor, Invalids and Social Affairs, January, 2018.

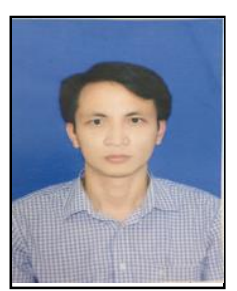

Phuong Huu Tung was born in 1985. Tung holds a master's degree in Economic Management in 2013. I completed my $\mathrm{PhD}$ program in Economic Management in 2018. Currently, I am qualified to advise and guide Master's students. PhD student majoring in Economic Management, Business Administration, Human Resource Management, Economics. I am a researcher interested in State management of human resources, human resource development; Education and human personality development; as well as issues related to human resource management in the organization. I have published ten international scientific articles related to Economics, human resource management; school education. I have also published 12 reference books, monographs, training textbooks for Hanoi University of Home Affairs and the Ministry of Education and Training. I have also received several awards for scientific research: outstanding achievements in scientific research from 2017 to 2020; received the Vietnam National Talented Young Scientist Award in 2020. 